\title{
Penyuluhan dan Pelatihan Kewirausahaan Sebagai Upaya Peningkatan Intensi Berwirausaha pada UKM "Bangkit"
}

\author{
Surahma Asti Mulasari' ${ }^{1}$, Fatwa Tentama², Sulistyawati ${ }^{3}$, Tri Wahyuni Sukesi ${ }^{4}$, Herman Yuliansyah $^{5}$, \\ Lu'lu' Nafiati6 \\ 1,2,3,4,5,6 Universitas Ahmad Dahlan \\ *e-mail: surahma.mulasari@ikm.uad.ac.id11, fatwa.tentama@psy.uad.ac.id², \\ sulistyawati.suyanto@ikm.uad.ac.id ${ }^{3}$,yunisukesi.fkmuad@gmail.com ${ }^{4}$ \\ herman.yuliansyah@tif.uad.ac.id55, lulu.nafiati@act.uad.ac.id6
}

\begin{abstract}
Covid-19 has had a major impact on all aspects of life and in all fields. Since Covid-19 was declared a pandemic, there have been many impacts of Covid-19 and the most pronounced impact has been on the Small and Medium Enterprises (SME) sector. The aim of this program is to provide counseling and training to increase entrepreneurial intentions in "Rise" SMEs in the midst of the Covid-19 pandemic. The target of this program is the people of Ngoro-Oro village who are members of UKM "Bangkit". The method used is in the form of counseling, training and direct practice (role play). Implementation of training for two days. The first day was in the form of counseling and entrepreneurial intention training which consisted of two sessions. The second day was the practice of processing local food ingredients into various types offood such as various kinds of chips (cassava chips, banana chips, spinach chips, etc.), various cakes such as bika and several types of brownies. The result of the program is that the community becomes aware of the concept of entrepreneurship, has the intention or desire to become entrepreneurial and has skills in processing local food ingredients into food products that have sale value.
\end{abstract}

Keywords: entrepreneurial intention, entrepreneurship training, entrepreneurship counseling

\section{Abstrak}

Covid-19 ini memberikan pengaruh yang besar terhadap segala aspek kehidupan dan segala bidang. Sejak Covid-19 ditetapkan berstatus pandemi banyak sekali dampak-dampak covid-19 yang ditimbulkan dan dampak paling terasa terjadi pada sektor Usaha Kecil dan Menengah (UKM). Tujuan dari program ini adalah memberikan penyuluhan dan pelatihan untuk meningkatkan intensi berwirausaha pada UKM "Bangkit" di tengah pandemi Covid-19. Sasaran program ini adalah masyarakat desa Ngoro-Oro yang tergabung dalam UKM "Bangkit". Metode yang digunakan yaitu berupa penyuluhan, pelatihan serta praktek langsung (role play). Pelaksanaan pelatihan selama dua hari. Hari pertama berupa penyuluhan dan pelatihan intensi berwirausaha yang terdiri dari dua sesi. Hari kedua berupa praktek pengolahan bahan makanan lokal menjadi beragam jenis makanan seperti aneka kripik (Kripik singkong, kripik pisang kripik bayam dan lain lain), aneka kue seperti bika dan beberapa jenis brownies. Hasil dari program adalah masyarakat menjadi paham tentang konsep berwirausaha, memilikin niat atau keinginan untuk berwirausaha dan memiliki ketrampilan dalam mengolah bahan makanan lokal menjadi produk makanan yang memiliki nilai jual.

Kata kunci: intensi berwirausaha, pelatihan berwirausaha, penyuluhan kewirausahaan

\section{PENDAHULUAN}

Pesatnya pertumbuhan penduduk akan diikuti dengan semakin meluasnya lapangan pekerjaan yang ada. Namun, lapangan pekerjaan yang ada seringkali tidak didukung dengan kemampuan ataupun potensi yang dimiliki oleh beberapa kalangan masyarakat. Beberapa masyarakat masih kesulitan untuk mengembangkan kemampuan yang dimilikinya dalam memanfaatkan berbagai lapangan pekerjaan tersebut. Peluang kerja tersebut sebenarnya banyak yang berada disekitar kita, namun kemampuan seseorang menangkap peluang tersebut tidak dimiliki. Saat ini situasi tersebut diperparah lagi dengan adanya pandemi Covis-19. Covid-19 ini memberikan pengaruh yang besar terhadap segala aspek kehidupan dan segala bidang. Sejak 
Covid-19 ditetapkan berstatus pandemi banyak sekali dampak-dampak covid-19 yang ditimbulkan dan dampak paling terasa terjadi pada sektor Usaha Kecil dan Menengah (UKM).

Salah satu UKM yang saat ini mengalami dampak dari pandemi Covid-19 adalah UKM "Bangkit" yang berada di Desa Ngoro-Oro, Patuk Gunung Kidul. UKM "Bangkit" merupakan kumpulan beberapa UKM yang ada di Desa Ngoro-Oro yang saat ini berupaya bangkit dari keterpurukan akibat dampak dari pandemi Covid-19. UKM "Bangkit" merupakan suatu komunitas yang memiliki sumber daya manusia yang memadai, namun masih kesulitan untuk mengembangkan unit usahanya. Masyarakat yang tergabung dalam UKM "Bangkit" ini mengalami penurunan niat berwirausaha, dan kesulitan menemukan dan mengembangkan jenis usaha yang tepat di era pandemi Covid-19 ini. UKM "Bangkit" membutuhkan penyuluhan dan pelatihan untuk meningkatkan kembali intensi (niat) berwirausaha pengurus dan anggota-anggotanya.

Wirausaha (entrepreneur) merupakan suatu kegiatan rutin yang menekankan pada manajemen, pengawasan serta inovatif (Casson, 2003). Kegiatan wirausaha yang dilakukan sebagai bentuk dari pemberdayaan untuk memperbaiki dan meningkatkan perekonomian yang ada. Sulistyawati et al. (2019) menjelaskan bahwa masyarakat memerlukan suatu bentuk dukungan untuk mengembangkan potensi yang dimiliki guna menopang perekonomian melalui pemberdayaan masyarakat. Dan untuk melakukan kegiatan wirausaha tersebut harus diawali dengan menumbuhkan intensi berwirasuahanya. Salah satu langkah awal untuk memulai wirausaha adalah dengan memiliki intensi berwirausaha. Intensi berwirausaha memainkan peran penting dalam tahap memulai bisnis (Garzón, 2010). Intensi berwirausaha mewakili komitmen individu untuk memulai usaha (Zapkau, Schwens, Steinmetz, \& Kabst, 2015). Intensi berwirausaha dipandang sebagai variabel yang dapat memengaruhi munculnya perilaku wirausaha di masa depan (Krueger, Reilly, \& Carsrud, 2000).

Beberapa bentuk pemberdayaan yang dapat dilakukan untuk membantu menumbuhkan serta meningkatkan intensi berwirausaha pada masyarakat melalui adanya penyuluhan, pelatihan dan bahkan praktek langsung. Melalui penyuluhan dan pelatihan ini juga akan membentuk karakteristik wirausaha pada pengurus dan anggota UKM "Bangkit". Temuan terdahulu menunjukkan bahwa karakteristik kewirausahaan secara signifikan mempengaruhi intensi berwirausaha (Kusmintarti, Thoyib, Maskie, \& Ashar, 2016). Berdasarkan uraian di atas, adapun tujuan dari program ini adalah 1) untuk meningkatkan intensif berwirausaha pada UKM "Bangkit", 2) memberikan penyuluhan dan pelatihan tentang intensi berwirausaha, 3) melakukan praktek berwirausaha berupa pelatihan olahan makanan sebagai bentuk dari follow up dari kegiatan berwirausaha.

\section{METODE}

Sasaran program ini adalah masyarakat desa Ngoro-Oro yang tergabung dalam UKM "Bangkit". Metode yang digunakan yaitu berupa penyuluhan, pelatihan serta praktek langsung (role play). Pelaksanaan pelatihan selama dua hari. Hari pertama berupa penyuluhan dan pelatihan intensi berwirausaha yang terdiri dari dua sesi, sesi pertama adalah penyuluhan konsep dasar berwirausaha dan peluang berwirausaha. Sesi kedua adalah pemanfaatan potensi-potensi lokal untuk berwirausaha. Hari kedua berupa praktek pengolahan bahan makanan lokal menjadi beragam jenis makanan seperti aneka kripik (Kripik singkong, kripik pisang kripik bayam dan lain lain), aneka kue seperti bika dan beberapa jenis brownies. Metode yang digunakan dalam pelaksanaan kegiatan ini adalah dengan melakukan penyuluhan, pelatihan serta praktek.

\section{HASIL DAN PEMBAHASAN}

Penyuluhan dan pelatihan diikuti oleh pengurus dan anggota UKM "Bangkit" yang ratarata pesertanya terdiri dari ibu-ibu. Hari pertama berupa penyuluhan yang diberikan oleh 
pemateri kepada peserta. Sesi pertama, peserta diberikan gambaran serta penjelasan tentang konsep dasar berwirausaha dan peluang berwirausaha. Kegiatan penyuluhan diselingi dengan sesi tanya jawab serta diskusi bersama. Warga terlihat antusias dan mendengarkan secara aktif pada tiap-tiap materi yang diberikan. Sesi kedua peserta diberikan wawasan dan pemahaman agar menyadari potensi-potensi lokal yang ada di sekitarnya agar dapat memanfaatkannya secara maksimal untuk berwirausaha. Tujuan dari kedua sesi ini adalah menumbuhkan intensi berwirasuaha peserta.

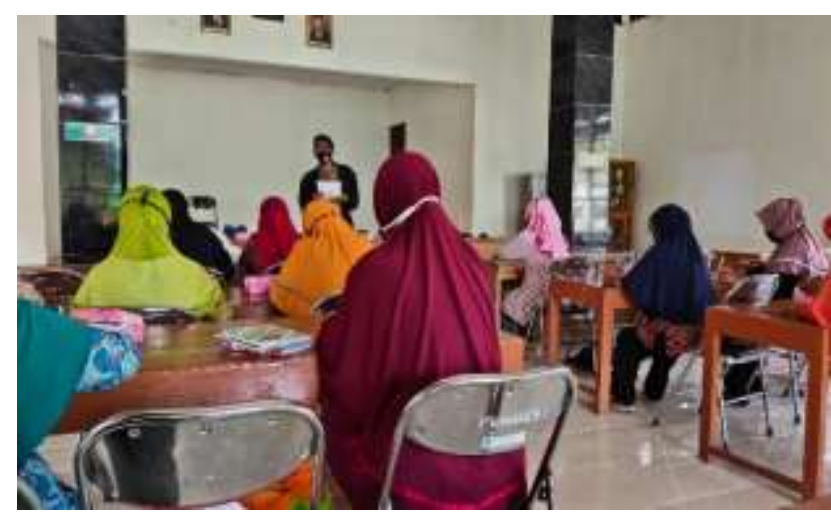

Gambar 1. Penyuluhan konsep dasar berwirausaha dan peluang berwirausaha

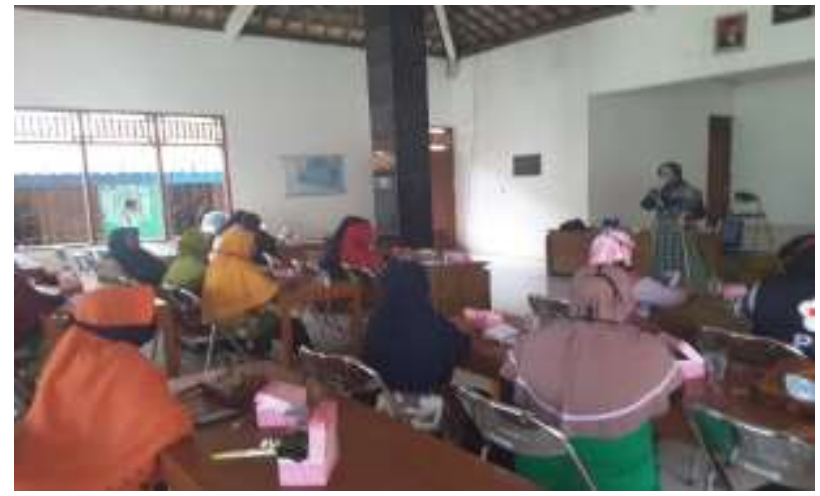

Gambar 2. Penyuluhan pemanfaatan potensi-potensi lokal untuk berwirausaha

Setelah sesi penyuluhan diberikan, hari selanjutnya, peserta melakukan praktek berwirausaha. Praktek yang dilakukan berupa praktek pengolahan bahan-bahan lokal seperti pisang, kentang, ubu-ubian, bayam, makanan yang dapat dijadikan sebagai bahan dasar yang akan diolah menjadi berbagai produk aneka makanan. Pada pelatihan ini juga diberikan peralatan yang juga merupakan bagian dari program ini yaitu mesin pembuat kripik, spiner peniris minyak dan sealer kemasan makanan karena tanpa peralatan tersebut maka pengolahan makanan ini menjadi terhambat. 


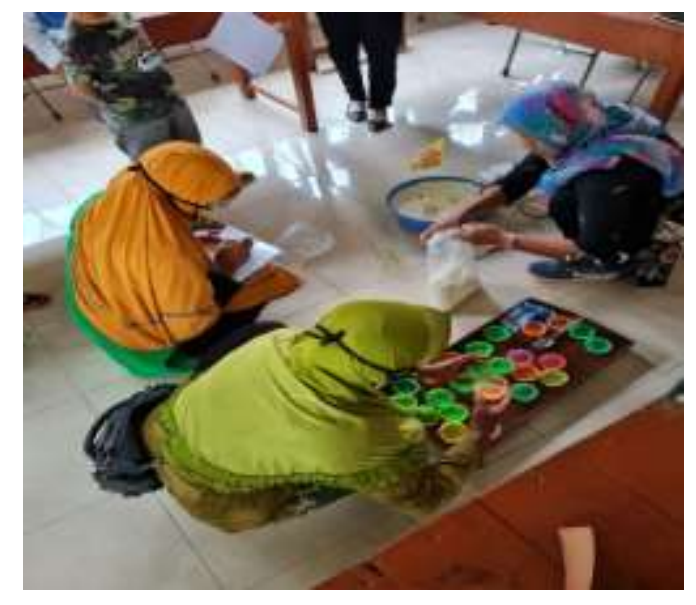

Gambar 3. Proses pembuatan adonan makanan

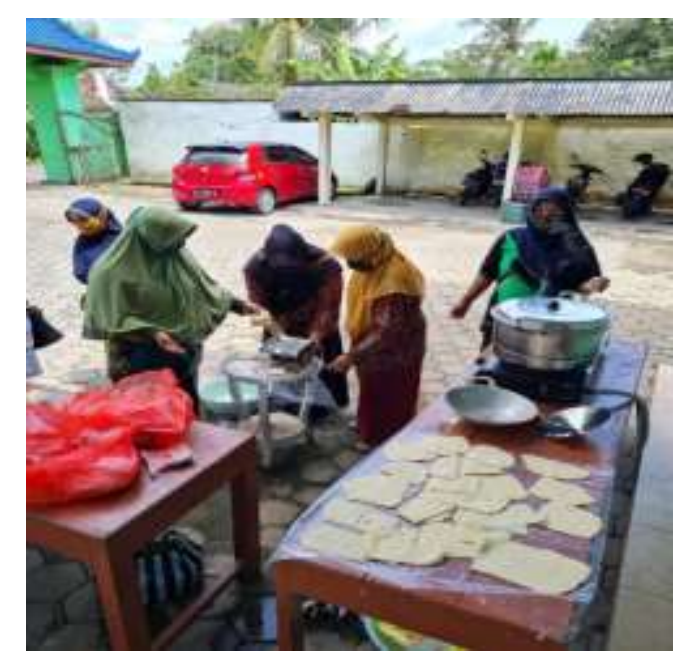

Gambar 4. Proses pencetakan adonan

Sesi berikutnya, adonan yang sudah selesai dibuat, dilakukan pencetakan agar adonan tersebut membentuk sebuah pola, sehingga bentuk adonan menjadi menarik. Selain itu, sebagian adonan juga diberikan pewarna makanan agar menarik dari segi bentuk maupun warnanya.

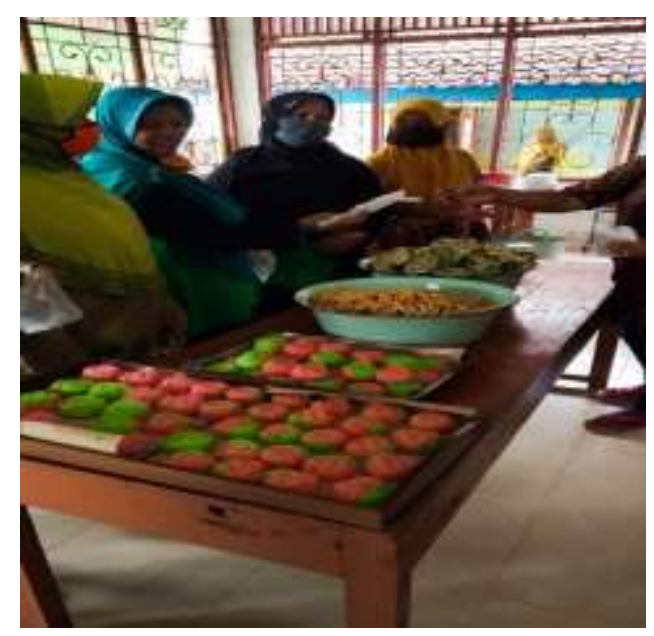

Gambar 5. Hasil olahan makanan 
Proses akhir dari praktek pelatihan pengolahan makanan yang telah dilakukan ialah terbentuklah produk hasil olahan makanan. Produk tersebut seperti aneka kripik (Kripik singkong, kripik pisang, kripik bayam dan lain lain), dan aneka kue seperti bika dan beberapa jenis brownies yang memiliki berbagai macam bentuk dan warna. Produk hasil olahan makanan tersebut yang nantinya akan dijual dan dimanfaatkan oleh UKM "Bangkit" untuk berwirausaha.

Dampak yang diperoleh dari adanya penyuluhan dan pelatihan yang dilakukan yaitu:

1.Memberikan pengetahuan dan ketrampilan tentang berwirausaha pada UKM "Bangkit".

2.Menumbuhkan intensi berwirausaha UKM "Bangkit".

3.Menumbuhkan inovasi baru dari hasil pengolahan bahan pangan lokal untuk berwirausaha.

\section{KESIMPULAN}

Kesimpulan yang dapat diperoleh dari pelaksanaan program ini adalah pengurus dan anggota UKM "Bangkit" memiliki pengetahuan dan ketrampilan dalam berwirasusaha sebagai modal dasar untuk memulai usaha baru di masa pandemi Covid-19. Dengan adanya pengetahuan dan ketrampilan berwirausaha tersebut maka akan menumbuhkan intensi (niat) berwirausaha pengurus dan anggota UKM "Bangkit".

\section{DAFTAR PUSTAKA}

Casson, M. (2003). The entrepreneur: An economic theory, second edition. The Entrepreneur: An Economic Theory, Second Edition, 1-271. https://doi.org/10.4337/9781843765639.

Garzón, M. D. (2010). A comparison of personal entrepreneurial competences between entrepreneurs and CEOs in service sector. Service Business, 4(3-4), 289-303. https://doi.org/10.1007/s11628-009-0090-6.

Krueger, N. F., Reilly, M. D., \& Carsrud, A. L. (2000). Competing models of entrepreneurial intentions. Journal of Business Venturing, 15(5), 411-432. https://doi.org/10.1016/S08839026(98)00033-0.

Kusmintarti, A., Thoyib, A., Maskie, G., \& Ashar, K. (2016). Entrepreneurial characteristics as a mediation of entrepreneurial education influence on entrepreneurial intention. Journal of Entrepreneurship Education, 19(1), 24-37.

Sulistyawati, S., Maulana, M., Tentama, F., M, S. A., \& Sukesi, T. W. (2019). Pendampingan Pembuatan Sistem Hidroponik dan Pengolahan Sampah Organik. JPPM (Jurnal Pengabdian Dan Pemberdayaan Masyarakat), 3(1), 77. https://doi.org/10.30595/jppm.v3i1.2876.

Zapkau, F. B., Schwens, C., Steinmetz, H., \& Kabst, R. (2015). Disentangling the effect of prior entrepreneurial exposure on entrepreneurial intention. 